\title{
A AUTOGESTÃO ENSINANDO E ENCENANDO: UM ESTUDO ETNOGRÁFICO EM UMA ORGANIZAÇÃO CULTURAL DE PORTO ALEGRE
}

\author{
THE SELF-MANAGEMENT TEACHING AND PERFORMING: \\ AN ETHNOGRAPHIC STUDY IN A CULTURAL \\ ORGANIZATION IN PORTO ALEGRE
}

Recebido 21/03/2011

Aceito 21/09/2011

Leonardo Flach ${ }^{1}$

\section{RESUMO}

Este artigo tem por objetivo analisar as formas de autogestão de organizações culturais, com base em um estudo etnográfico em uma organização cultural de Porto Alegre. O estudo ressalta a importância de ações de autogestão em organizações culturais como forma de manter a identidade cultural regional e o desenvolvimento local, sendo uma forma alternativa de prática organizacional, de relação com a esfera privada e com o Estado. O esforço teórico é pela busca das origens sociológicas do conceito, a partir das perspectivas de Marx e Proudhon, abrangendo a revisão sobre outra possibilidade de gestão de organizações. Dentro da comunidade acadêmica, o conceito adquire novamente espaço, por buscar outras formas de organização na sociedade e desenvolvimento local, em detrimento às pressões do modelo neoliberal e da globalização. Conclui-se que organizações culturais autogeridas possuem potencial de ação frente às disfunções do capitalismo vigente, tratando, com princípios democráticos, uma estrutura horizontal e flexível.

Palavras-chave: Autogestão. Organizações culturais. Etnografia.

\footnotetext{
1 Professor Adjunto da Universidade Federal de Santa Catarina. Bacharel e Mestre em Administração pela UFSC e Doutor em Administração pela UFRGS, com doutorado sanduíche na Freie Universität Berlin (Alemanha). E-mail: leoflach@hotmail.com
} 


\section{ABSTRACT}

This article aims to analyze the forms of cultural and autonomous social movements, based on an ethnographic study in a theater group in Porto Alegre. The study emphasizes the importance of some manage actions in cultural organizations in order to maintain cultural identity and regional development, in a new form of relationship with the private and state sphere. The theoretical effort is the search of the sociological origins of the concept, from the perspectives of Marx and Proudhon, covering also a revision of contemporary authors. Within the academic community the concept takes space, in the search for other forms of organization in society and against the pressures of the neoliberalism and globalization. It is concluded that cultural organizations have potential to act again the problems of the capitalism, dealing with democratic principles, and with a horizontal and flexible structure.

Keywords: Autonomous social contra-movement. Cultural organizations. Ethnography.

\section{INTRODUÇÃO}

Existe uma preocupação sobre novas formas de gestão, desenvolvimento local, novos desafios da gestão social e da organização econômica diante da lógica neoliberal vigente no momento. São diversos os tipos de organizações, tais como Organizações Não Governamentais (ONGs), Organizações da Sociedade Civil de Interesse Público (OSCIPs), empresas mistas de capital privado e estatal, cooperativas, empresas de capital social, consórcios, empresas com participação acionária de funcionários, organizações de autogestão, empresas de participação comunitária, dentre outras. Dessas formas organizacionais, esta pesquisa pretende enfocar as organizações autogeridas. A autogestão consiste em uma proposta de uma nova dinâmica na organização do trabalho, com diminuição de níveis hierárquicos e ampliação das possibilidades de tomada de decisão. Ela se mantém sob a égide da Economia Solidária e emerge como uma proposta de enfrentamento das disfunções do modelo capitalista, como caminho alternativo para o problema do desemprego e como um novo olhar para as relações mercantis.

Cresce o interesse por organizações e grupos que mantenham o sentido de território, de uma identidade com a cultura e a manifestação dos interesses coletivos, perseguindo a possibilidade da autoconsciência da sociedade brasileira. Assim, põe-se em destaque uma sociologia engajada com a realidade nacional, de modo a desconsiderar a redução sociológica, baseada na adaptação de modelos prontos e herméticos (GUERREIRO RAMOS, 1996). Além disso, parte-se do pressuposto de que a arte possui a capacidade de expressar anseios e ideias a partir de sua atuação. Dessa forma, analisar uma organização cultural adquire relevância teórica e prática, resultando no seguinte problema de pesquisa: como ocorrem as formas de organização do trabalho entre os membros na organização do espetáculo "Ópera do Malandro"?

Frente a essas considerações, respeitando a complexidade do tema e os diversos fatores envolvidos, foi estabelecido como objetivo principal deste estudo entender como ocorrem as formas de organização do trabalho entre os membros na organização do espetáculo "Ópera do Malandro". Assim, acompanhando os ensaios do grupo, buscou-se conhecer a estruturação e a distribuição do trabalho, de forma a caracterizar a prática de autogestão.

Este artigo consiste em um estudo etnográfico realizado em uma organização cultural de Porto Alegre, que, no momento, ensaiava o espetáculo "Ópera do Malandro", de Chico Buarque. Na análise dos dados, foram abordados não somente o texto, mas o contexto estudado. Os ensaios do grupo para o espetáculo surgiram como cenário de observação e análise desta etnografia.

Notadamente nos estudos da antropologia e cultura organizacional, o método etnográfico é consagrado pelas possibilidades de aprofundamento na análise dos dados em um determina- 
do contexto social. Nos últimos anos, este método tem sido difundido em pesquisas na área de administração, por autores como Mascarenhas (2002), Barbosa (2003), Rocha e Barros (2006) e Cavedon (2010).

\section{AUTOGESTÃO: CONCEITO E ORIGEM}

Autogestão é um modelo de administração voltado para uma dinâmica alternativa das relações de poder nas organizações, pautado na proposta de estruturas hierárquicas mais flexíveis e horizontais. Características marcantes deste modelo de gestão seriam: elevado grau de autonomia do trabalhador, trabalho flexível, ação coletiva, cooperação, democracia, ideais de transformação social e propostas alternativas frente ao desemprego.

O conceito de autogestão surgiu a partir de Karl Marx e Pierre Proudhon. Apesar de nenhum dos autores abordar esse conceito, ambos trabalharam com o conceito de associativismo e lançaram as sementes para a criação de uma nova forma de pensar e agir frente ao modelo capitalista. As ideias de Proudhon eram opostas ao liberalismo e denunciavam a organização econômica, governamental e educacional do capitalismo, propondo a criação de sociedades cooperativas de produção. O pensamento de Proudhon era voltado para uma reorganização da sociedade, tendo como princípio a justiça. Para o autor, a justiça seria a base da harmonia social (PROUDHON, 1923). Paralelamente, Marx e Engels apoiaram seus pensamentos e foram os principais críticos do socialismo utópico, fundando assim o chamado socialismo científico.

Segundo Proudhon (1923), o homem deveria abandonar a condição econômica e moral baseada na sujeição a outros homens, pois isso levaria à desarmonia social. A nova sociedade deveria apoiar-se no mutualismo, uma forma de cooperação baseada em associações. Guerreiro Ramos (1953), mais tarde, baseia-se nessas premissas e complementa esses estudos trazendoos para a realidade brasileira, defendendo que a formação econômica, política e social do Brasil se caracteriza como dependente e erigida sob os pilares do colonialismo cultural, da subordinação mental da elite nativa em relação à cultura dos países dominantes. A visão etnocêntrica ancorada na cultura europeia e norte-americana teria disseminado, entre os brasileiros, uma concepção alienada da "realidade nacional", homogeneizadora e propagadora de um universalismo abstrato, que relegava a especificidade do "fenômeno nacional" (GUERREIRO RAMOS, 1953).

Essa visão alienante, conforme Guerreiro Ramos (1953), acaba desconsiderando a originalidade da estrutura social, tomando-a simples reflexo, uma imitação das determinações reinantes dos países colonizadores. Tal modalidade de pensamento intenta uniformizar o diferente, apagar os antagonismos, isolar o estranho, abafar o ruído, sincronizar os tempos históricos. A vivência nacional, situada em uma outra fase cultural, reclama fidelidade à sua própria temporalidade e instaura uma existência cultural própria.

Guerreiro Ramos (1996) considera importante o uso da razão sociológica, da capacidade da sociologia usar seu instrumental, de rever-se, refletir a respeito de si e com relação à estrutura social à qual se encontra vinculado, sobre seus métodos e objetivos. Ao método crítico capaz de proceder a uma reflexão dessa natureza, assimilando criticamente as contribuições teóricas "importadas", Guerreiro Ramos denominou "redução sociológica". A redução sociológica, para o autor, consiste em uma "atitude parentética", não-espontânea, que põe entre parênteses os fenômenos, recusando a afirmação ou aceitação imediata das percepções, desnaturalizando a apreensão social e impondo filtros ao pensar. A redução sociológica tem como pressuposto a "universalidade dos enunciados gerais da ciência", todavia propaga o "caráter subsidiário da produção científica estrangeira", bem como o comprometimento do soció- 
logo com a realidade em questão e no que diz respeito à fase cultural na qual a sociedade se encontra (GUERREIRO RAMOS, 1996, p. 72).

Reunindo as contribuições de alguns autores que auxiliaram na construção do conceito de autogestão, formulou-se o quadro 1 .

Quadro 1 - Contribuições teóricas para a formação do conceito de autogestão

\begin{tabular}{|c|c|c|}
\hline Autor (ano) & Concepção de autogestão & Influências epistemológicas \\
\hline Lima (2011) & $\begin{array}{l}\text { Exercício coletivo do poder na concepção de } \\
\text { gestão social, baseada na autonomia, } \\
\text { empreendedorismo, associativismo e princípios } \\
\text { sociais. }\end{array}$ & Sociologia \\
\hline $\begin{array}{l}\text { Castanheira e Pereira } \\
\qquad(2008)\end{array}$ & $\begin{array}{l}\text { Negação da burocracia e sua composição que } \\
\text { artificialmente separa um grupo de comandantes } \\
\text { de um grupo de comandados. }\end{array}$ & Sociologia \\
\hline Proudhon (1923) & $\begin{array}{l}\text { Sociedade organicamente autônoma, baseada nas } \\
\text { autonomias de grupos se autoadministrando, cuja } \\
\text { vida exige a coordenação, mas sem excessiva } \\
\text { hierarquização. O ideal seria uma sociedade } \\
\text { organizada de maneira autônoma nas funções } \\
\text { econômicas de produção e nas funções políticas. }\end{array}$ & Filosofia política e Economia \\
\hline Marx (1974) & $\begin{array}{l}\text { Forma de associativismo, de pensar e agir frente } \\
\text { às disfunções do modelo capitalista. }\end{array}$ & Sociologia e Economia \\
\hline $\begin{array}{l}\text { Guerreiro Ramos } \\
\qquad(1996)\end{array}$ & $\begin{array}{l}\text { Estrutura social caracterizada pela autonomia dos } \\
\text { empreendimentos, emancipação e igualdade de } \\
\text { seus membros. Faz uso da razão sociológica, da } \\
\text { capacidade de rever-se, refletir a respeito de si. }\end{array}$ & Administração e Sociologia \\
\hline
\end{tabular}

A ideia de organizações de autogestão não é nova e teria a mesma idade da empresa industrial, sendo derivada do conflito entre capital e trabalho (GUTIERREZ, 1991). No Brasil, segundo a análise da literatura sobre autogestão realizada por Nascimento (1999), ela se dividiria em três fases. A primeira, no final dos anos 70, versava sobre comissões de fábrica e autonomia dos trabalhadores. A segunda fase ocorreu no início dos anos 80 e tratava da experiência da autogestão nos países do Leste Europeu, principalmente na Iugoslávia. O autor localiza a terceira fase nos anos 90, nos debates sobre a economia solidária. Atualmente, os debates continuam a ocorrer, principalmente no colóquio sobre Poder Local, no Encontro de Estudos Organizacionais da Anpad (ENEO) e no Encontro Nacional da Pós-Graduação em Administração (ENANPAD).

As organizações autogeridas se constituem como uma rede de pessoas que deliberadamente agrupam-se em torno de objetivos comuns, compartilhando solidariamente os recursos disponíveis, empenhando-se para produzir e reproduzir relações úteis e duráveis entre si e com outros atores, que possam contribuir para alcançar os objetivos compartilhados (BOURDIEU, 1998).

A cooperação exige a necessidade de confiar nos outros e também ter a certeza de que se pode contar com a confiança dos outros. Quando os atores são incapazes de assumir compromissos entre si, eles têm que renunciar a muitas oportunidades de proveito mútuo. Portanto, há a necessidade de que estejam presentes, nas organizações autogeridas, os elementos de um capital social, conceito que "diz respeito a características da organização social, como confiança, normas e sistemas, que contribuam para aumentar a eficiência da sociedade, facilitando as 
ações coordenadas. O capital social facilita a cooperação espontânea" (PUTNAM, 2000, p. 177).

Bourdieu (1998) identifica efeitos que são visíveis quando os indivíduos participantes de certos grupos apresentam resultados desiguais a partir de recursos econômicos ou culturais equivalentes. Para designar os fundamentos desses efeitos sociais, o autor também propôs a noção de capital social, como um conjunto de recursos atuais ou potenciais que estão ligados à posse de uma rede durável de relações, que podem ser consideradas como a vinculação a um grupo formado por elementos reconhecidos por possuírem propriedades comuns. Além disso, estão sujeitos a ligações permanentes e úteis, fundamentadas em trocas materiais e simbólicas e não apenas nas relações de proximidade no espaço físico, econômico e social. Nessas condições, o volume de capital social que um determinado agente consegue estocar depende da extensão de sua rede de relações e do volume de capital econômico, cultural ou simbólico que os participantes dessa rede possuem. É com base nesse padrão de solidariedade que se garante a concentração do capital social, para obter lucros materiais ou simbólicos.

Bourdieu (1998) ainda complementa que o capital social sofre uma influência do capital econômico e cultural possuído por um agente e pelos outros agentes a quem está ligado. As vantagens geradas pelo pertencimento a um determinado grupo estão ligadas a uma base de solidariedade existente e geradora de tais vantagens, que são tratadas pelo autor como lucros materiais proporcionados pelos serviços provenientes das relações do grupo e lucros simbólicos associados ao prestígio de pertencer a determinados grupos raros e reconhecidos socialmente. Assim, o estabelecimento de uma rede de relações depende de um trabalho de "instauração e de manutenção que é necessário para produzir e reproduzir relações duráveis e úteis, aptas a proporcionar lucros materiais ou simbólicos" (BOURDIEU, 1998, p. 68).

A autogestão na Economia Solidária pode ser abordada de duas maneiras não excludentes: a) pode ser considerada como um sistema autogestionário, o qual envolve os preceitos sociológicos da autogestão, abordando os aspectos ideológicos, políticos e sociais; e b) pode se tratar de um processo de autogestão cujo eixo de análise consiste nas relações e nas características técnicas dos grupos envolvidos (processos, ferramentas, entre outros, para o desenvolvimento dos trabalhos) (CAVEDON; FERRAZ, 2004). Para este estudo, o foco de análise incidiu predominantemente neste segundo aspecto.

A possibilidade de êxito de organizações autogeridas depende de práticas sociais que se relacionam com compromissos sociais, atitudes e comportamento dos indivíduos. Nesse sentido, é interessante recuperar a contribuição de Putnam (2000) quando comenta sobre a virtude cívica e a característica democrática, ao analisar o desenvolvimento da região norte da Itália em relação à região sul. O autor atribui o maior desenvolvimento da região norte ao surgimento de uma comunidade cívica, onde a maioria das pessoas acompanha os assuntos de interesse da comunidade e valoriza a vida política distante de clientelismos e personalismos. Ademais, acreditam no governo popular e na igualdade como um princípio natural. A organização das redes sociais e das políticas ocorre horizontalmente, valorizando a solidariedade, o engajamento cíviCo, a cooperação e a honestidade. No sul da Itália, não foi encontrado o mesmo sentimento cívico. Ao contrário, segundo o autor, há uma organização hierárquica da vida pública e considera-se que a coisa pública é um problema "do outro", o que determina a ausência de participação nas deliberações sobre o bem público, e, se eventualmente isso ocorre, é em função de interesses pessoais e não da coletividade (PUTNAM, 2000). 


\section{PROCEDIMENTOS METODOLÓGICOS}

Esta pesquisa está baseada em um estudo etnográfico, método de pesquisa pioneiramente trabalhado por Malinowski (1976), que se recusou ao limite de uma simples descrição da instituição nativa da tribo Kula e abordou um processo que abrangia a transação de objetos úteis, organização social, mitos e rituais mágicos. Para isso, decidiu "imergir" na cultura dos povos das Ilhas Trobriand, convivendo diariamente com os membros do grupo social, realizando observações e relatos. O método de Malinowski (1976) considera a complexidade da natureza humana, observando o ser humano em sua totalidade, ciente de que ele é uma criatura dotada de paixões tanto quanto de razão.

Por método etnográfico, entende-se uma atividade de pesquisa situada no próprio campo de estudo, por prolongado período de tempo, contato direto com o objeto de análise, seguido por uma sistematização em formato de texto da experiência observada. De acordo com Clifford (2002, p. 21), "a etnografia está, do começo ao fim, imersa na escrita. Esta escrita inclui, no mínimo, uma tradução da experiência na forma de texto".

Fazer a etnografia incide em novas interpretações da realidade, a partir das visões do nativo e do observador. Seria o equivalente a ler um manuscrito "estranho, desbotado, cheio de elipses, incoerências, emendas suspeitas e comentários tendenciosos, escritos não como os sinais convencionais do som, mas com exemplos transitórios do comportamento modelado" (GEERTZ, 1989, p. 7). Concebe-se a possibilidade que os "horizontes semânticos em confronto - o do pesquisador e o do nativo - abram-se um ao outro, de maneira a transformar tal confronto em um verdadeiro encontro etnográfico" (OLIVEIRA, 1998, p. 24).

O período de realização das observações ocorreu no primeiro semestre de 2006. Foram realizadas, dessa forma, observações diretas no ambiente de trabalho, bem como conversas informais com pessoas envolvidas no espetáculo.

Para a análise das observações, procurou-se atentar para as considerações de Oliveira (1998, p. 18): "[...] enquanto no olhar e no ouvir realiza-se nossa percepção, será no escrever que nosso pensamento exercitar-se-á da forma mais cabal, como produtor de um discurso que seja tão criativo como próprio das ciências voltadas à construção da teoria social".

\section{ANÁLISE DOS DADOS: LIÇÕES QUE A AUTOGESTÃO ENSINA E EN- CENA}

Um dos exemplos de autogestão que foram bem-sucedidos e que influenciaram os movimentos de autogestão no Brasil foi o caso da construção de casas populares no Uruguai. A ideia surgiu na década de 80, e foram construídas mais de 10.000 habitações por meio da autogestão. O mutirão autogerido consiste em um trabalho coletivo, em que as lideranças, organizadas entre as comunidades, gerenciam todo o processo da construção das moradias, em uma autoridade definida de baixo para cima, proporcionando aos indivíduos decisões diversas, que garantem o espírito de comunidade durante o processo: trata-se de uma construção autônoma da sociedade civil, que, com o apoio e financiamento do poder público, equaciona a produção de moradias com a participação de moradores.

Essa superação se explica pelas formas democráticas de gestão e pela capacidade de articulação e coordenação (governança) com diferentes instituições públicas e privadas. Nesse sentido, a autogestão e as formas que assumem as relações de trabalho são uma inovação que viabiliza a sustentabilidade dessas empresas. 
Na história da classe operária, podem-se traçar cinco ondas de longa duração que apontam a perspectiva da autogestão:

a) o movimento dos "visionários", como Robert Owen e a gestão operária; Fourier e os falansterios; Louis Blanc e as oficinas nacionais; Lassale e as oficinas autogestionárias; Proudhon e o mutualismo; Williams Morris e os pequenos grupos espontâneos; Theodor Hertzka e as comunas autogestionárias;

b) grupos e movimentos sociais, como marxismo, anarquismo, sindicalismo e socialismo cooperativo;

c) revoluções ou experiências práticas de autogestão: a Comuna de Paris (1871); a Revolução Russa (1905); a Revolução Socialista de Outubro de 1917; a Revolução Húngara de 1919; a Revolução Alemã de 1919; a Revolução Italiana de 1919; a Revolução Espanhola de 1936-1939; a Revolução Argelina de 1962; as revoluções no Leste europeu, na Hungria em 1956 e na Polônia em 1956; a revolução Theca da "Primavera de Praga" em 1968; o movimento social Solidarnosc; o movimento na Polônia em 1980-1981; e diversas experiências de práticas autogestionárias na Europa nos anos 60 e 70, sobretudo na França (tipo LIP), na Itália e em Portugal;

d) novos sistemas de autogestão, como as experiências de organização na produção (cogestão, consultas coletivas, delegados sindicais etc.) e a autogestão como sistema na lugoslávia, a partir de 1950;

e) uma onda mais recente, caracterizada pela existência em diversos países, do movimento da Economia Solidária.

Este artigo enfoca um grupo cultural que está presente dentro desta última onda de autogestão, ou seja, dentro do campo do terceiro setor e da Economia Solidária. Trata-se de um grupo cultural autogerido, que, no momento, estava preparando o espetáculo "Ópera do Malandro", de Chico Buarque, que, por sua vez, consiste em uma das marcas da cultura brasileira. A "Ópera do Malandro" foi escrita em 1978, inspirada na "Ópera do Mendigo", de John Gay, e na "Ópera dos Três Vinténs", de Bertolt Brecht e de Kurt Weil. O espetáculo lotou inteiramente o Teatro Carlos Gomes, tradicional reduto das revistas na antiga capital do Brasil, e rapidamente se configurou como um dos grandes fenômenos de público e crítica já vistos na cidade do Rio de Janeiro. Capturou a unanimidade da emoção de quem assistiu, impressionou pela lotação sempre antecipada da casa e foi abençoada pelo carinho do próprio autor.

O cenário da peça é a Lapa carioca das prostitutas e da pancadaria. O período é a década de 40, com a guerra assolando o mundo e ecoando no Brasil. A "Ópera do Malandro" põe em cena a rivalidade entre o contrabandista Max Overseas e Fernandes de Duran, o dono dos prostíbulos da Lapa. Bem no meio da briga, está Terezinha, a filha única de Duran e de Vitória, que se casa com Max sob as bênçãos do Inspetor Chaves, o Tigrão, que "trabalha" para ambos os contraventores. O casamento é o golpe final na família Duran: o desgosto dos pais de Terezinha - e naturalmente a ameaça aos negócios - é o gatilho da trama em que todos tentam tirar vantagem de todos. A peça criou ainda outros personagens inesquecíveis, como Geni e Lucia (a filha de Tigrão e rival de Terezinha). Ao todo, são 20 personagens, além de músicos, maestro e equipe de cenografia.

No caso do espetáculo de Porto Alegre, o projeto foi aprovado pela Lei Municipal de Incentivo à Cultura, mas, segundo o diretor artístico, conta com poucos recursos. Ou seja, apesar de o projeto ter sido aprovado pela lei, poucos patrocinadores até o momento forneceram auxílio. Dessa forma, o diretor artístico do espetáculo comentou que ainda não sabe ao certo com quantas pessoas poderá contar em sua equipe, mas, apesar de já estar trabalhando com a equipe de atores e alguns músicos, afirma que talvez tenha que diminuir o número destes. Vale 
lembrar que a ópera envolve um grande número de atores, orquestra, maestro, entre outros. No entanto, a carência financeira fez com que o grupo se mobilizasse para arrecadação de fundos para a realização do espetáculo. Dessa maneira, organizaram, dentro do período do primeiro semestre de 2006, saraus com música e poesia, para ajudar a arrecadar fundos.

O local de ensaio é uma grande sala localizada nos fundos de uma Escola de Música de Porto Alegre. O espetáculo envolve música, dança, encenação, além de ser representado por um grupo de cantores, músicos e intérpretes que, em cena, representam alguns aspectos típicos do jeitinho brasileiro.

Barbosa (1992) recusa tomar o jeitinho brasileiro como "folclore", "sobrevivência cultural" ou mesmo "costume inocente", destinado a desaparecer com a presença de um suposto desenvolvimento econômico ou evolução histórica. A autora encara o jeitinho brasileiro como um procedimento estrutural obrigatório e inevitável quando se trata de articular o mais forte com o mais fraco, a carência de quem não tem poder com o eventual poder de quem o tem e, além disso, como a regra geral abstrata, universal e impessoal, com a compreensão humana, calorosa e solidária que nasce das relações pessoais, contextualizadas e particulares.

O espetáculo ensaiado pelo grupo se caracteriza pela utilização constante de técnicas de Bertold Brecht, para evitar a identificação do público com os personagens, fazendo com que as pessoas que o assistem possam refletir sobre a realidade política do país. Dessa forma, os membros tentam passar, por meio de seus personagens, uma imagem da cultura brasileira, do malandro, daquela pessoa que consegue tirar vantagem e viver a vida de maneira alegre, mesmo que haja a necessidade do jeitinho. Mas os ensaios da peça também demonstravam o lado negativo do malandro, de uma malandragem que, às vezes, consiste em mentir, em extorquir, em abusar de poder, entre outros. Dessa maneira, os integrantes se identificam com o espetáculo e com seu trabalho, passando uma mensagem ao público que o assiste.

De qualquer maneira, é importante lembrar que essa imagem refletida no espetáculo consiste em um dos padrões de cultura existentes no Brasil, captado por Chico Buarque para seu espetáculo. Benedict (s.d.) defende que, em cada sociedade, existem determinados padrões de cultura. Para isso, a autora defende que quase nenhuma feição cultural é compreensível quando separada do conjunto de que faz parte. Para Benedict (s.d.), deve-se compreender o indivíduo como um ser que vive na sua cultura, e a cultura como vivida pelos seus indivíduos.

Baseando-se no exemplo do estudo em três diferentes culturas, Benedict (s.d.) defende que nem todas as culturas são definidas por um caráter dominante, mas parece provável que, quanto mais íntimo é o conhecimento dos impulsos culturais que determinam o comportamento do indivíduo, tanto mais reconhecer-se-á que nelas dominam certos refreamentos de emoção, certos ideais de conduta, que explicam atitudes que aparentam anormalidade (quando observadas do ponto de vista da civilização atual).

Além de representar um padrão de cultura da sociedade brasileira, a encenação através da música e da interpretação, por parte dos membros do grupo, aparenta fornecer a eles uma ideia de liberdade. Como comenta Bourdieu (1998, p. 146), "ter seu próprio destino, ou se deixar tratar como número, eis o dilema que cada um, certamente, deve resolver em nossos dias, mas está sozinho para poder decidir [...]". Além disso, o autor acrescenta que

[...] queremos falar do homem livre, tal como sai das mãos de Deus. Ele não é exceção, nem representa uma elite. Longe disso: porque ele se esconde em todos os homens e as diferenças existem apenas na medida em que cada indivíduo sabe atualizar esta liberdade recebida como um dom (BORDIEU, 1998, p. 146).

Rev. Adm. UFSM, Santa Maria, v. 4, n. 3, p. 378-389 set./dez. 2011 
Bourdieu (1998) posteriormente complementa que, iguais em liberdade, os homens são desiguais na capacidade de utilizar autenticamente sua liberdade, e somente uma "elite" pode se apropriar das possibilidades universalmente oferecidas de se ter acesso à liberdade de "elite". Vale ressaltar que esse termo, utilizado como "elite" por Bourdieu (1998), não diz respeito ao grupo com maior poder aquisitivo ou status. Fazendo a comparação com o espetáculo analisado, talvez inclusive o artista ou o malandro representado no espetáculo seja a figura emblemática de alguém que seja mais livre e, portanto, mais pertencente a essa "elite" do que alguém com simplesmente maior poder aquisitivo.

Neste momento, talvez alguns se reportem à pergunta já realizada por Barbosa (1999): como mudar uma cultura? Segundo a autora, os termos manejar, controlar, alterar e direcionar, frequentes no vocabulário sobre mudança e nos títulos de artigos e livros sobre o assunto, transmitem a preocupação com o desenvolvimento de uma tecnologia de intervenção na realidade que seja realmente efetiva. Mas a autora enfatiza que "a cultura não é algo que se possa transformar numa tecnologia, assim como as tecnologias de produção, que podem ser adotadas, modificadas, descartadas, etc." (BARBOSA, 1999, p. 139).

Segundo Barbosa (1999), no sentido antropológico, cultura significa um conjunto de mecanismos simbólicos utilizados para organizar a realidade. Não existem organizações, países ou indivíduos desprovidos de cultura. Segundo os antropólogos, a cultura não é algo que se produz em uma empresa ou se leva para dentro dela. É um sistema de símbolos e significados de domínio público, em cujos contextos as tarefas e práticas de determinado grupo podem ser descritas de forma inteligível para as pessoas que dela participam ou não.

Considera-se que a arte, além de representar aspectos da cultura de determinado povo ou região, contribui para a formação da identidade. Segundo Velho (1999), a construção da identidade é problema universal da sociedade. Em todo e qualquer grupo tribal, tradicional ou moderno, definem-se e classificam-se categorias sociais, sejam famílias, clãs, linhagens, classes, grupos de status etc.

Observou-se que os membros realizavam ensaios longos, que duravam, no mínimo, duas horas, sem uma preocupação extrema com término em horário pontual, além do fato de que os ensaios seriam realizados por um semestre inteiro, já que o espetáculo seria apresentado somente no fim de novembro. Com um cachê (que, na linguagem do artista, significa o pagamento pela apresentação) que ainda não estava definido, esse modo de fazer a arte pela arte, sem preocupação com o retorno financeiro, permite, de certa forma, uma comparação com a Teoria da Dádiva, de Mauss (2003), uma vez que, no estudo, o autor defendia que a modalidade de troca efetuada no kula não se fundamentava em um mero cálculo utilitário de lucros ou perdas, pois, na verdade, vinha de encontro com necessidades emocionais e estéticas de ordem mais elevada que os simples atendimentos aos requisitos da natureza animal.

Do mesmo modo, a realização do espetáculo, o modo de fazer a arte pela arte, sem um retorno equânime e obsessivo pelo lado financeiro, permite inferir certa racionalidade inerente no grupo que não esteja exclusivamente voltada ao cálculo de meios e fins. Bourdieu (1998), na segunda parte de seu livro, garimpa algumas fórmulas e conceitos sintéticos do que seja a arte, o simbólico, o poder do simbólico. As análises dos ritos de passagem e das representações sociais proporcionam evidências de grande densidade cognitiva que lhe permitem tematizar as condições em que sucede a gênese do simbólico, a produção da ilusão, do fetiche, ou melhor, da legitimidade que reveste a arte e o artista.

Observou-se que os membros do grupo legitimavam a figura do líder, respeitando sempre todos os conselhos e críticas dele, fazendo sempre silêncio no momento em que este dirigia algum comentário ou mesmo alertava para o início de determinada atividade. Os próprios 
membros não se sentiam constrangidos em ser criticados pelo diretor artístico e, pelo contrário, inclusive alguns faziam questão, em determinados momentos, de comentar: "Ficou melhor agora? Posso repetir mais uma vez?". Essa vontade de fazer cada vez melhor, essa atitude perfeccionista, gera uma grande motivação, no grupo, em fazer arte, em ultrapassar seus limites do teatro e da encenação, de realmente passar uma mensagem para a plateia. Esses pontos comentados poderiam ser relacionados com o poder simbólico de Bourdieu (1998), que, segundo o autor, permite exprimir o sofrimento, a decepção, a alegria, todos os sentimentos associados aos tempos fortes do ciclo da vida de um grupo social e, em um novo registro, veicular os anseios, as expectativas, as identidades e demais sinalizações pertinentes com que os grupos sociais buscam afirmar sua diferença por meio dos encantamentos instilados em sua definição dos mistérios da vida e do mundo.

\section{CONSIDERAÇÕES FINAIS}

A realização de um empreendimento em autogestão depende de diversos fatores, como a necessidade da utilização de sistemas inovadores e não-convencionais, por exemplo. Esses sistemas inovadores podem reduzir o custo da mão de obra, proporcionar maior desenvolvimento tecnológico, diminuir desperdícios no uso do capital. Assim, as economias geradas podem ser utilizadas para a melhoria de outros aspectos e carências dos projetos de autogestão. Considera-se também essencial a existência de três aspectos nos sistemas de autogestão: associação, assessoria competente na área e poder público. Esses três elementos devem caminhar juntos, mas não devem ser subordinados um ao outro.

Identificou-se, neste estudo etnográfico, que os integrantes tinham autonomia em suas decisões, liberdade para escolher os rumos da organização. A área de assessoria não centralizava as decisões e garantia a socialização de seus conhecimentos. Constatou-se uma relação da organização com o governo, efetuada por meio de projetos culturais. No entanto, o primeiro setor estava encarregado de auxiliar no fornecimento e controle dos recursos financeiros, mas as decisões artísticas eram tomadas pela organização cultural. Observou-se que outras ações para captação de recursos eram tomadas, tais como a promoção de saraus de música e poesia, com o intuito de angariar fundos que auxiliassem nos custos do espetáculo.

É glorioso perceber, na organização do espetáculo "Ópera do Malandro", a valorização do trabalho em equipe, democracia, horizontalidade de níveis hierárquicos e desenvolvimento de laços interpessoais que contribuem para a construção da cidadania e do capital social. Este capital, enquanto incorpora a prática do associativismo, da confiança, da transparência nas relações, do sentimento cívico e da cooperação, ainda está para ser construído na maioria das organizações.

Observou-se, nos membros pesquisados, a vontade de atingir a liberdade em seu sentido amplo, realizando a arte como uma forma de comunicação, reflexão e manifestação. Por meio da autogestão, o grupo procura defender a cultura brasileira em seu sentido mais verdadeiro, defendendo valores locais e encarando o discurso hegemônico de uma cultura globalizada. Para isso, realiza espetáculos que tenham como tema a realidade brasileira, de modo a inspirar a reflexão por parte do espectador.

Observou-se também a existência de pouca centralidade na tomada de decisões. Considera-se que a gestão centralizada constitui um dos fatores que contribuem para que as organizações culturais não sobrevivam como organizações autogeridas. Além disso, alerta-se para o fato de que, apesar de considerar como pontos positivos abrir as portas para voluntários e mem- 
bros que tenham interesse em participar, o crescimento acentuado de novos membros sem um programa de capacitação continuada, capaz de também socializar os novos membros nos princípios da organização, bem como a possível falta de compromisso dos membros com a organização, pode impedir a perenidade dessas organizações na luta pelo território e desenvolvimento local.

Um comportamento que deve ser evitado nas organizações culturais que pretendem manter-se como autogeridas incide no comportamento patrão-empregado. Esse fato não foi observado na organização do espetáculo "Ópera do Malandro". De qualquer maneira, é válido firmar que essa seria uma prática contraditória com um modelo que preconiza a participação de todos os membros. Uma situação como essa talvez ocorra pela ausência de capital social, reforçando a prática de valores individualistas, que não privilegia as relações pessoais e a responsabilidade pelo coletivo. A postura individualista traz consigo a desvalorização do sentimento de comunidade, de seus valores, onde prevalece a solidariedade e a colaboração. No processo de gestão de uma organização cultural, onde os interesses dos diversos segmentos devem ser contemplados, a colaboração e a solidariedade constituem valores importantes.

Verificou-se que a participação e o compromisso, pautados também em relações horizontais, mas respeitando a figura do líder, são características identificadas no grupo analisado. Constatou-se uma definição de normas claras de conduta, relações interpessoais pautadas pela prática da confiança, bem como compromisso para a construção artística de qualidade. Acredita-se que a presença dessas características permite que se acumule um capital que não é de cada um, mas da coletividade, que surge da intensidade da interação entre seus membros para a sobrevivência da organização. Esse capital é o que se denomina capital social. A sobrevivência dessas organizações, que atendem aos interesses coletivos, depende da intensidade das relações entre seus membros e da sua participação na condução dos processos onde todos assumam sua responsabilidade para a realização de um trabalho cada vez melhor. Essa é uma questão central nas organizações culturais, e foi justamente esse interesse que levou a investigar esses fatores no espetáculo.

Os resultados da pesquisa permitem inferir que um dos fatores que possivelmente mantém o grupo em coesão e harmonia, resistindo inclusive a problemas como falta de verbas, consiste no fato de possuir um grande capital social acumulado. Um dos exemplos que ilustra essa coesão consiste no fato de todos os membros do grupo permanecerem em ensaios exaustivos, com duração de, no mínimo, duas horas, e terem se engajado na promoção de saraus e noites com poesia, para que, com o dinheiro da arrecadação dos mesmos, pudessem investir na produção do espetáculo. Ou seja, essa postura ativa e a relação de amizade e companheirismo dos membros do grupo contribuem para o fortalecimento do capital social.

Sugere-se, para futuros estudos, que outras organizações culturais sejam analisadas por meio do método etnográfico, no intuito de observar aspectos minuciosos e peculiares dessa forma de gestão. Esse campo de pesquisa contribui para fazer frente ao conceito denominado por Guerreiro Ramos (1996) de redução sociológica, perseguindo a possibilidade da autoconsciência da sociedade brasileira, colocando em combate uma sociologia engajada com a realidade nacional.

A grande contribuição que se pode contar com um grupo que procura fazer a encenação de uma ópera de maneira a tentar passar, da forma mais fidedigna e eficiente, a cultura, sem demonstrar preocupação em saber o quanto receberiam em troca em termos financeiros, sem se preocupar com o horário para o término do ensaio, consiste na forma mais pura de fazer a arte pela arte. É possível que a burocratização e a profissionalização tornem mais difícil que esses elementos continuem sendo observados da mesma forma, mas é preciso continuar so- 
nhando com utopias com os pés no chão. Afinal, como dizia o poeta Chico Buarque de Holanda, "Nem toda loucura é genial, como nem toda lucidez é velha".

\section{REFERÊNCIAS BIBLIOGRÁFICAS}

BARBOSA, L. Marketing etnográfico: colocando a etnografia em seu devido lugar. Revista de Administração de Empresas, São Paulo, v. 43, n. 3, Sept. 2003. Disponível em: $<$ h t t p : / / w w w. s c i e I o . b r / scielo.php?script $=$ sci arttext\&pid $=$ S0034$75902003000300007 \& \operatorname{lng}=\mathrm{en} \& \mathrm{nrm}=\mathrm{iso}>$. Acesso em: 9 jul. 2011.

Igualdade e meritocracia: a ética do desempenho nas sociedades modernas. Rio de Janeiro: FGV, 1999.

O jeitinho brasileiro: a arte de ser mais igual do que os outros. Rio de Janeiro: Campus, 1992.

BENEDICT, R. Padrões de cultura. Lisboa: Livros do Brasil, [s.d.].

BOURDIEU, P. A economia das trocas lingüísticas. São Paulo: Edusp, 1996.

Escritos de educação. Organização de Maria Alice Nogueira e Afrânio Catani. 4. ed. Rio de Janeiro: Vozes, 1998. 251 p.

CASTANHEIRA, M. E. M.; PEREIRA, J. R. Ação coletiva no âmbito da economia solidária e da autogestão.

Revista

Katálysis, Florianópolis, v. 11, n. 1, June 2008. Disponível em: <http:// www.scielo.br/scielo.php?script=s c i_a rttext\&pi d = S 1414 49802008000100011\&lng $=\mathrm{en} \& \mathrm{nrm}=\mathrm{iso}>$. Acesso em: 13 jul. 2011.

CAVEDON, N.; FERRAZ, D. As culturas organizacionais de uma loja autogestionada de economia popular solidária de Porto Alegre. In: ENCONTRO NACIONAL DOS PROGRAMAS DE PÓS-GRADUAÇÃO EM ADMINISTRAÇÃO, 25., 2004, Curitiba. Anais... Curitiba, [S.n.]: 2004. 1 CD-ROM.
CAVEDON, N. R. "De frente pro crime": cultura organizacional e socialização dos peritos ingressantes no departamento de criminalística do instituto-geral de perícias do Rio Grande do Sul. Revista de Administração Mackenzie, São Paulo, v. 11, n. 4, Aug. 2010. Disponível em: <http:// www.scielo.br/scielo.php?script$=\mathrm{sci}_{\text {arttext\& }}$ pid=S1678$69712010000400003 \& \operatorname{lng}=$ en $\& n r m=$ iso $>$. Acesso em: 9 jul. 2011.

CLIFFORD, J. A experiência etnográfica: antropologia e literatura no século XX. Rio de Janeiro: Ed. da UFRJ, 2002.

\section{GEERTZ, C. A interpretação das culturas.} Rio de Janeiro: LTC, 1989.

GUTIERREZ, L. G. Autogestão, participação, propriedade e salário. Revista de Administração, São Paulo, v. 26, n. 4, p. 14-23, out./ dez. 1991.

GUERREIRO RAMOS, A. O processo da sociologia no Brasil: esquema de uma história das ideias. Rio de Janeiro: [s.n.], 1953.

A redução sociológica. 3. ed. Rio de Janeiro: Ed. da UFRJ, 1996.

MALINOWSKI, B. Argonautas do pacífico ocidental. São Paulo: Abril Cultural, 1976.

LIMA, J. C. Participação, empreendedorismo e autogestão: uma nova cultura do trabalho? Sociologias, Porto Alegre, v. 12, n. 25, Dec. 2010. Disponível em: http:// w w w . S c i e l o . b r / scielo.php?script $=$ sci_arttext\&pid $=$ S1517$45222010000300007 \& \operatorname{lng}=\mathrm{en} \& \mathrm{nrm}=\mathrm{iso}>$. Acesso em: 8 July 2011.

MARX, K. O capital. Livro III. Trad. Port. Rio de Janeiro: Civilização Brasileira, 1974.

MASCARENHAS, A. O. Etnografia e cultura organizacional: uma contribuição da antropologia à administração de empresas. Revista de 